POLLACK PERIODICA

An International Journal for Engineering and Information Sciences

DOI: $10.1556 / 606.2016 .11 .3 .5$

Vol. 11, No. 3, pp. 43-60 (2016)

www.akademiai.com

\title{
SIMPLIFIED CALCULATION OF NON-REPEATING THERMAL BRIDGES OF THE TYPICAL CENTRAL- EUROPEAN SMALL SUBURBAN HOUSES
}

\author{
${ }^{1}$ Dániel BAKONYI, ${ }^{2}$ Gergely DOBSZAY \\ Department of Building Constructions, Faculty of Architecture, Budapest University of \\ Technology and Economics, Müegyetem rkp. 3, H-1111 Budapest, Hungary \\ e-mail: ${ }^{1}$ dbakonyi@epsz.bme.hu, ${ }^{2}$ gdobszay@epsz.bme.hu
}

Received 22 April 2016; accepted 28 July 2016

\begin{abstract}
A new calculation method for deriving easy-to-use equations for the simplified calculation of non-repeating thermal bridges is presented and tested on several constructional variants of a common Central-Europe building type. Through the identification the main parameters affecting the difference between the one- and multidimensional heat transfer coefficients of facades their number is reducible. The method's accuracy compares favorably to current calculations. A new formulation is introduced for the calculation of the total heat transfer coefficient of the external thermal envelope incorporating the proposed simplified thermal bridge calculation method and the window's in-situ heat transfer coefficients.
\end{abstract}

Keywords: Thermal bridges, Building energy calculation, Monte Carlo simulation

\section{Introduction}

The precise calculation of the heat transfer coefficient of the external building fabric is a key issue of all building energy computations. One of the main difficulties lies in the treatment of thermal bridges in opaque constructions. A thermal bridge is defined as a part of the external thermal envelope where heat fluxes become multi-dimensional, as opposed to a theoretical infinite planar assembly where heat fluxes are strictly parallel. There are two distinct groups of thermal bridges to differentiate:

- repeating thermal bridges, which are inhomogeneous parts in the external constructions demonstrating a periodically recurring pattern within a single 
planar assembly (e.g. wooden studs in lightweight walls or wall-ties in cavity walls); and

- non-repeating thermal bridges, which occur at the large scale details and junctures of different constructions (e.g. wall corners, slab to wall connections, etc.), where the interior and exterior surface dimensions are not equal and/or where materials with different thermal conductivities meet.

Heat losses from repeating thermal bridges are usually incorporated into either the thermal conductivity of the materials (e.g. the thermal conductivity of a masonry must represent the joint characteristics of both brick and mortar), or into the U-value of the construction (e.g. the correction for mechanical fasteners in external thermal insulation composite systems, [1]). Repeating thermal bridges are not a subject of this article.

The precise calculation of non-repeating thermal bridges (henceforth just thermal bridges) is described e.g. in the standard EN-ISO-10211, [2]. To follow this method the $2 \mathrm{D}$ or $3 \mathrm{D}$ thermal models of all details in question have to be solved: some numerical solution of the stationary heat conduction equation over the detail with the appropriate material properties and with thermal boundary conditions described in the standard. From the results of these simulations (i.e. the surface integral of the calculated heat flux densities at the boundaries) it is easy to calculate the precise thermal transmittance of the investigated details. A good summary of the different numerical calculation approaches to thermal bridge simulations is found in [3], see also [4].

While software to perform these calculations are now easily available and the necessary computational load is usually minimal for contemporary machines the manual workload to build the models themselves and the level of expertise required is still quite large. As a result precise thermal bridge simulations are still very rarely used by everyday practitioners. To try to address this problem some researchers use different machine learning approaches to try to find approximate relationships between the relevant parameters and the thermal transmittance of characteristic thermal bridge types to eliminate the need for thermal simulations. Another approach using Artificial Neural Networks is found in Orosz and Csanaky [5]. Meanwhile the regulation of most countries permits some kind of simplified treatment of thermal bridges in heat transfer calculations. Usually a certain correction is applied to the calculated one-dimensional overall thermal transmittance (U value) to account for multidimensional effects. This correction is prescribed without actually performing thermal bridge simulations or using a detailed thermal bridge atlas. A good summary of simplified calculation methods in EU countries is given in [6]. In the context of the Hungarian building energy regulation [7] the following simplified method is used in calculating the total thermal transmittance of the thermal envelope:

$$
\dot{Q}_{\text {transm }}=\sum_{i=1}^{n} A_{i} U_{R, i}+\sum_{j=1}^{m} l_{j} \psi_{j}
$$

where $Q_{\text {transm }}[\mathrm{W} / \mathrm{K}]$ is the total heat transfer coefficient of the external thermal envelope; $A_{i}\left[\mathrm{~m}^{2}\right]$ is the internal area of surface $i ; U_{R, i}\left[\mathrm{~W} / \mathrm{m}^{2} \mathrm{~K}\right]$ is the effective thermal transmittance value of surface $i ; l_{j}[\mathrm{~m}]$ is the length of the plinth detail $j$ (slab-on-grade 
perimeter) or basement wall; $\psi_{, j}[\mathrm{~W} / \mathrm{mK}]$ is the linear thermal transmittance value of the plinth or basement wall detail.

In Eq. (1) the multi-dimensional heat transfer effects are not treated explicitly, with the singular exception of the heat losses towards the ground. The focus of this article is on the thermal bridge calculation in parts of the thermal envelope not in contact with the soil. For an introduction to the Hungarian and European ground heat loss calculations, an analysis of their accuracy is referred to [8]. In order to avoid huge calculation errors in Eq. (1) that the neglect of the thermal bridges would bring an $U_{R}$ effective thermal transmittance value is prescribed instead of the simple $U$ value. This contains a prescribed thermal bridge correction factor, which is supposed to account for the excess heat flow caused by multi-dimensional effects. $U_{R}$ is calculated as:

$$
U_{R}=(1+X) U
$$

where $U_{R}\left[\mathrm{~W} / \mathrm{m}^{2} \mathrm{~K}\right]$ is the effective thermal transmittance value; $X[-]$ is the thermal bridge correction factor; and $U\left[\mathrm{~W} / \mathrm{m}^{2} \mathrm{~K}\right]$ is the thermal transmittance value of the planar construction without thermal bridges (as calculated acc. to EN ISO 6946 [1]). Eqs. (1) and (2) are based on the implicit assumption that the following equality is approximately true:

$$
\sum_{i=1}^{n}\left(1+X_{i}\right) U_{i} A_{i} \approx \sum_{i=1}^{n} U_{i} A_{i}+\sum_{j=1}^{m} \psi_{j} l_{j}+\sum_{k=1}^{p} \chi_{k},
$$

where $X_{i}[-]$ is the thermal bridge correction factor of construction $i ; U_{i}\left[\mathrm{~W} / \mathrm{m}^{2} \mathrm{~K}\right]$ is the thermal transmittance value of the planar construction $i$ without thermal bridges; $A_{i}\left[\mathrm{~m}^{2}\right]$ is the surface area of construction $i ; \psi_{j}[\mathrm{~W} / \mathrm{mK}]$ is the linear heat transfer coefficient of the linear thermal bridge $j ; l_{j}[\mathrm{~m}]$ is the length of thermal bridge $j$ and $\chi_{k}[\mathrm{~W} / \mathrm{K}]$ is the heat transfer coefficient of the 3D thermal bridge $k$.

The values of $X$ to be used on which the accuracy of the whole method depends are prescribed in the regulation (section II. 3b in [7]) and are shown in Table I. To use the Hungarian method the geometry of the individual surfaces must be calculated with their internal dimensions and the ratio of the total length of thermal bridges to the total surface area $(\Sigma l / A)$ determined. The type of thermal bridges whose lengths are to be summed up is also specified in the regulation for each construction type. For external walls the value of $X$ depends only on whether the wall has a continuous thermal insulation layer or not and on the value of $\Sigma l / A$. No other possible influencing factors (e.g. the construction of the wall, the quality of the details, ...) are taken into account. The method is the same for all buildings type and it is unknown how its values were originally derived.

In a previous article [9] an extensive thermal bridge atlas was used to investigate the accuracy of the Hungarian simplified thermal bridge calculation method. This research focused on the external walls of $19^{\text {th }}$ century Central-European urban apartment 
buildings with either internal, external or no thermal insulation. By the results in most cases the simple calculation is very inaccurate. In [10] Talmon and Csoknyai reached similar conclusions for the case of prefabricated 'panel' buildings. Simplified calculations in other countries can suffer from the same lack of accuracy as demonstrated in [11] by Theodosius and Papadopulos for the Greek energy code and in [12] by Berggren and Wall in a more comprehensive study among Norwegian practitioners. It appears that having just a handful of discrete values for thermal bridge correction factors (e.g. seen in Table I) cannot represent the entire range of possible building geometries and constructions.

\section{Table I}

Values $X$ in [1] for external walls and the limits for their selection according to $\Sigma l / A$

\begin{tabular}{|c|c|c|c|}
\hline & \multicolumn{3}{|c|}{$\Sigma l / A[1 / \mathrm{m}]$} \\
\hline geometrical limits for choosing the correction factor & $<0.8$ & $0.8-1.0$ & $>1.0$ \\
\hline & \multicolumn{3}{|c|}{$X[-]$} \\
\hline external wall with continuous thermal insulation & 0.15 & 0.20 & 0.30 \\
external wall without continuous thermal insulation & 0.25 & 0.30 & 0.40 \\
\hline
\end{tabular}

In [13] a new method was proposed to generate more reliable thermal bridge correction factors for the external walls of buildings. This new methodology tried to account for all of the influences on the correct value of the thermal bridge correction factor. The extension of this method to other building types requires the calculation of many possible building facades, which is most practically achieved with the parametric generation of virtual buildings as demonstrated in [14]. The following algorithm is proposed to try to account for all of the parameters:

1) For every building typology describe the characteristic façade type, determine its geometrical parameters (e.g. internal headroom, frequency of connecting internal partition and/or loadbearing walls, typical openings and their distances, etc.) and their expected range (minimum and maximum values and if knowable their statistical distribution);

2) Determine the constructional variants and parameters to be investigated for the building typology (e.g. wall type and thickness, type position thickness and conductivity of thermal insulation, etc.) and define their expected range (discrete types or continuous variables with minimum and maximum values and if knowable their statistical distribution);

3) Make a list of the typical (non-repeating) thermal bridges on the façade type in point 1) and perform the necessary thermal simulations to obtain their linear thermal transmittance values for all the possible constructional variants determined in point 2). When applicable perform this simulation for both well and poorly designed details (e.g. continuous or discontinuous thermal insulation in window reveals, etc.);

4) With the data compiled in points 1) 2) and 3) perform a Monte Carlo simulation: generate virtual facades based on all the previously described variables with a 
sufficiently large sample size and calculate their exact multi-dimensional total heat transfer coefficients. From this data calculate the correct value of the thermal bridge correction factor $X$ (using equation (3));

5) Analyze the data to find easy to use relationships between the thermal bridge correction factor $X$ and the basic parameters of the building typology (e.g. the $\Sigma l / A$ value, the thermal resistance of the insulation, the wall, etc.);

6) Check the accuracy of the result by comparing the values calculated in point 4) and the ones calculated with the method derived in point 5).

For a single building type it was demonstrated that this method can have a much better accuracy than using the existing simplified calculation in the current Hungarian regulation. The method can basically compress all the data in a detailed thermal bridge atlas into a few equations and parameters that are much easier to use for everyday practitioners. However, the results are only valid for the specific building typologies, parameters and parameter ranges they were derived for and must be published together with these. The user must be able to make the judgement whether a given formula is valid for his or her case. To this end any simplified calculation equations should always be published together with a description of the building and constructional types they were derived for. The difficulties with the method are the following:

1) the method is only applicable for buildings that are reasonable to typify (the variability between different thermal bridge types and their abundance on the façade is limited);

2) it needs to be derived for different building types individually;

3) a large number of independent parameters for a certain building type requires a large number of thermal bridge simulations to derive the new thermal bridge correction factors (although this work is only needed once);

4) building types with many independent parameters will probably require a more complex system of correction factors (e.g. many such factors) to maintain accuracy.

Points 1) and 2) seem unescapable and therefore indicate a reasonably well defined area for the used method. Given the contemporary trends in architecture and the plethora of new construction materials and solutions it is hard to imagine that any simplified thermal bridge calculation could possibly deliver accurate results to most new designs. Many existing building however can easily be grouped into characteristic building typologies, with similar façade geometries and constructional solutions (Fig. 1).

For these buildings the practical usability of the methods seems to rely largely on how much the possible number of independent constructional parameters in the description of a building type can be reduced while still maintaining accuracy. In this article the earlier work is continued by applying the proposed method to a more ubiquitous existing Central-European building type and investigate the possibilities for reducing the total number of independent parameters. 

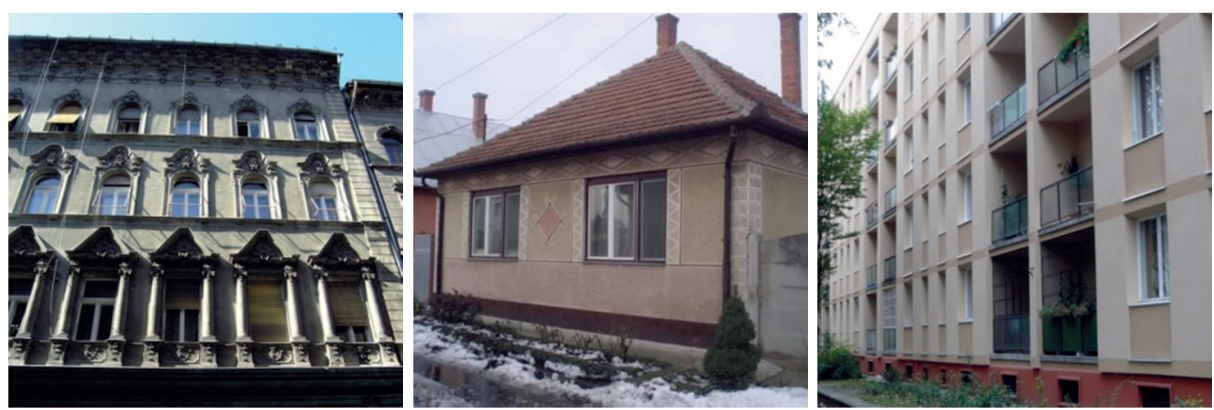

Fig. 1. Three very typical building from the Hungarian architectural heritage: $19^{\text {th }}$ century apartment building (left), 'cube houses' (middle), 'block houses' (right)

\section{Investigated building type and parameter sets}

For this study a typical suburban or rural building type was chosen to be investigated: colloquially known in Hungary as 'cube houses'. This type of small detached houses were built in large numbers after the second world war in Central- and Eastern-European countries, based on very similar type plans, in an effort to replace more traditional buildings that were deemed outdated by the political thinking of the time. These buildings are not completely identical in their floorplan or structures, as construction techniques varied according to what materials were at hand, but there is still a significant commonality between them. The vast majorities share a single storey, approximately square floor plan with two external and one internal loadbearing walls and are topped by an unheated and unused attic with a hip roof, which is usually close to a pyramid shape. The floor level is elevated from the ground with a large plaster, cast- or quarry-stone covered footing. The bedrooms, living rooms and kitchens have large, horizontally aligned windows, most commonly with two large symmetric windows oriented towards the street. The main entrance door is either connected to a terrace or is in a small lobby protruding from the main body of the building.

Due to the small size of the buildings it is possible to generate complete façade geometries for the calculations with the use the main geometrical variables in Fig. 2 . and the algorithm summarized in Fig. 3.

Each virtual building has four facades numbered 1-4 assigned sequentially as either loadbearing or not, starting with the main street facing façade with the characteristic double windows. Then a secondary façade (hiding the kitchen and possible other bedrooms), a rear façade with the small openings usually oriented towards the neighbor and finally the entrance with either a terrace or a lobby is generated. Additional connecting internal loadbearing and partition walls are assigned to each façade element according to its type. The number of openings on the rear and secondary facades can vary.

The generated façade geometries were not intended to correspond to real floor plans, the only goal was to capture the characteristic of thermal bridges on the external walls. A few examples of the generated virtual façade geometries are shown in Fig. 4. 


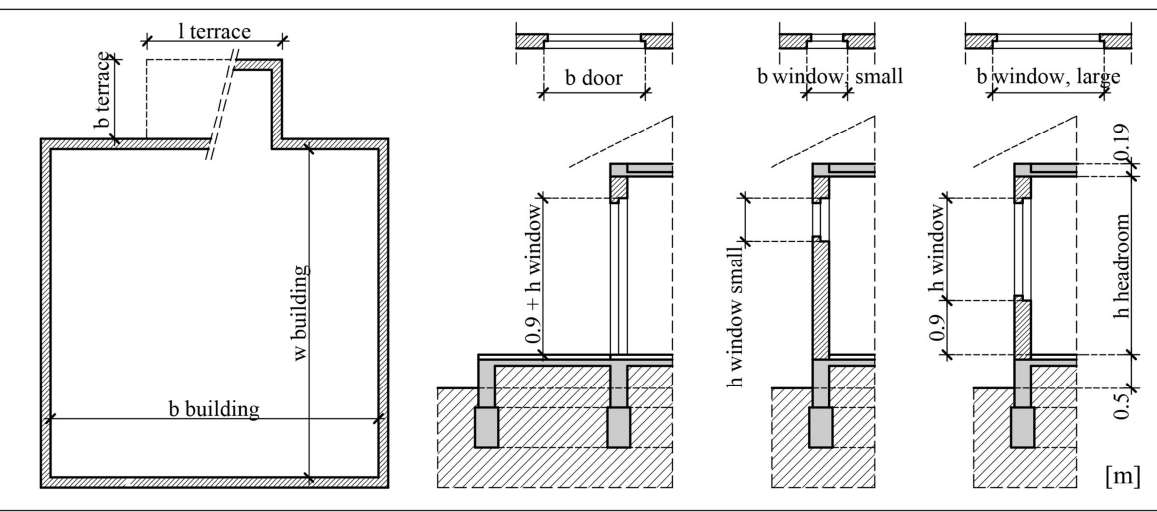

Fig. 2. 'Cube house' building type - geometrical parameters, where $b_{\text {building }}$ is the lenght, $w_{\text {building }}$ is the width of the building, $h_{\text {headroom }}$ is the internal headroom, $l_{\text {terrace }}$ is the length, $b_{\text {terrace }}$ is the width of the terrace, $b_{\text {door }}$ is the width of the terrace door, $b_{\text {window,small }}$ is the width $h_{\text {window,small }}$ is the height of the small windows, $b_{\text {window,big }}$ is the width, $h_{\text {window, large }}$ is the height of the big windows

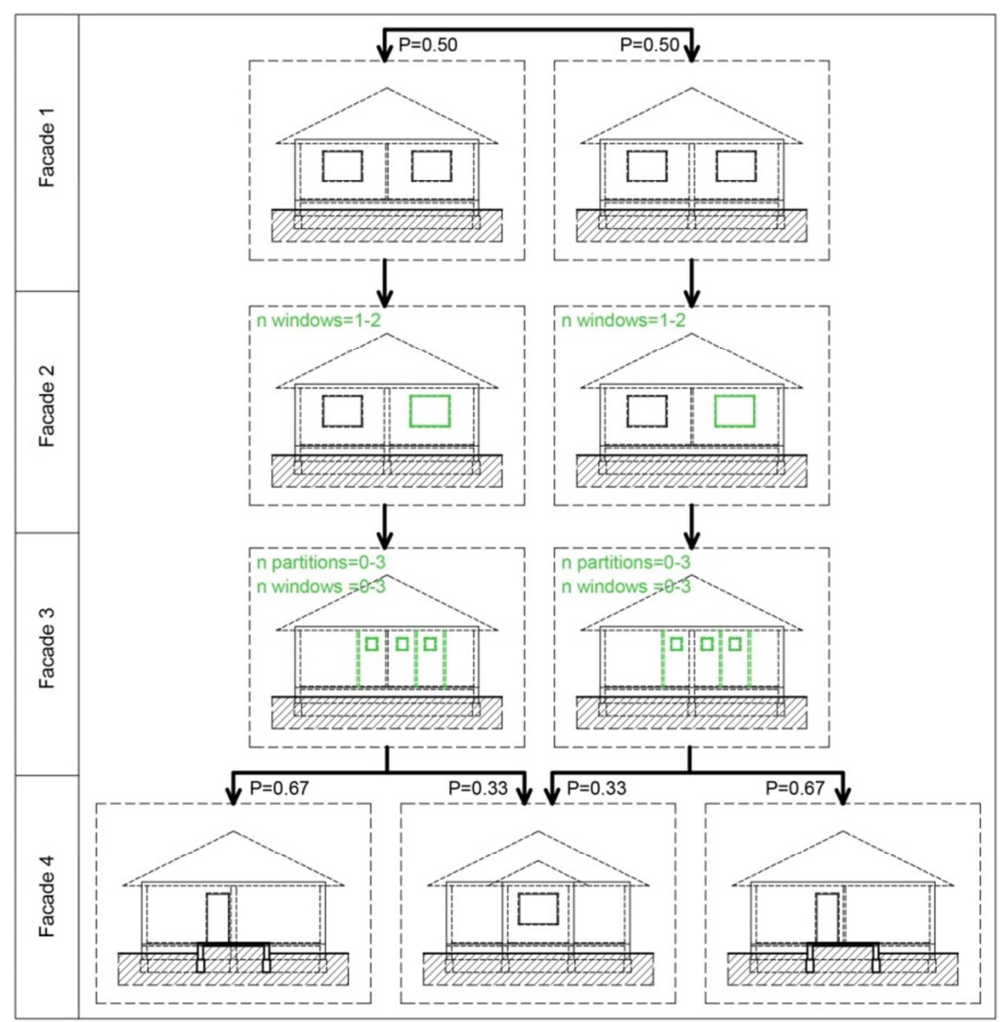

Fig. 3. 'Cube house' building type - geometry generation 

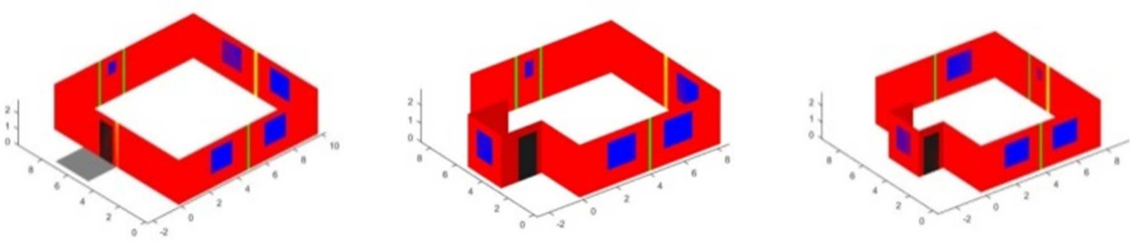

Fig. 4. 'Cube house' building type - examples of the generated virtual facades

As it was already mentioned these types of buildings were built using whatever constructional materials were available at the time and place. For the current investigation two common variants: a 38 [cm] thick solid clay brick masonry and a $25[\mathrm{~cm}]$ thick aerated clay brick masonry. These have roughly the same $U$ value, which is a good way to investigate the dependence of thermal bridging on wall thickness. The floor is always $50[\mathrm{~cm}]$ above ground, uninsulated and has a concrete plinth. The slab over the main floor is a prefabricated RC beam construction with concrete trays filled with slag between the beams. Slab and walls are connected with a reinforced concrete ring-beam without perimeter thermal insulation. The lintel beams are prefabricated reinforced concrete elements. The walls and the attic slab are either uninsulated, or have an external insulation of $8-20[\mathrm{~cm}]$ in $2[\mathrm{~cm}]$ increments. The thermal conductivity of the insulation is $\lambda=0.04[\mathrm{~W} / \mathrm{mK}]$. These parameters are summed up in Table II.

Table II

'Cube house' building type - constructional parameters

\begin{tabular}{|l|c|c|}
\hline & Solid clay brick masonry & Aerated clay brick masonry \\
\hline$t_{\text {wall }}[\mathrm{m}]$ & 0.38 & 0.25 \\
$\lambda_{\text {wall }}[\mathrm{W} / \mathrm{mK}]$ & 0.78 & 0.50 \\
$R_{\text {wall }}\left[\mathrm{m}^{2} \mathrm{~K} / \mathrm{W}\right]$ & 0.487 & 0.50 \\
$\lambda_{\text {ins }}[\mathrm{W} / \mathrm{mK}]$ & 0.04 & 0.04 \\
$t_{\text {ins }}[\mathrm{m}]$ & $0-0.08-0.10-0.12-0.16-$ & $0-0.08-0.10-0.12-0.16-0.20$ \\
& 0.20 & $0-2-2.5-3-4-5$ \\
$R_{\text {ins }}\left[\mathrm{m}^{2} \mathrm{~K} / \mathrm{W}\right]$ & $0-2-2.5-3-4-5$ & $1-$ traditional w. \\
window & $1-$ traditional w. & 2 - contemporary w. \\
& $2-$ contemporary w. & 3 - trad.w. + roller shade \\
& & 4 - cont.w. + roller shade \\
\hline
\end{tabular}

The main thermal bridges of the masonry are shown in Fig. 5. The wall-to-slab and plinth details have both a good and a bad quality variant. This is a necessary variable to investigate as the thermal insulation of the wall-to-slab details is often not continuous because people try to avoid disturbing the existing roof and eaves construction, while in the case of the plinth the thermal insulation often ends at the bottom of the actual masonry as people try to preserve an existing stone footing around the building. 


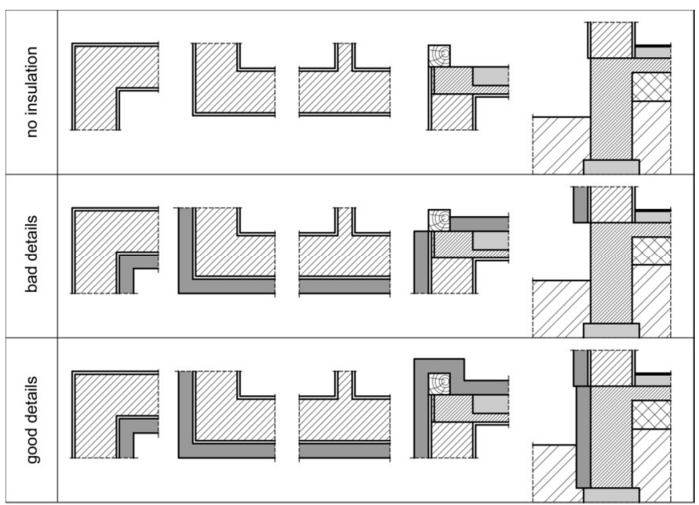

Fig. 5. 'Cube house' building type - thermal bridges (opaque construction)

The openings are either traditional double-skinned Central-European box type windows (most commonly known as Kastenfenster in German) or single skin contemporary constructions (wood or plastic), either with or without an inbuilt roller shutter. The window types are numbered 1-4 and their installation joints/thermal bridges are summed up in Fig. 6. All window details have original (no insulation) and insulated good and bad quality variants. The position of the window frames in the masonry was taken as a representative example, actual geometries can differ.

\section{Monte Carlo simulation results}

Based on the description of the building type (parameter set, virtual façade geometry generation algorithm and detailed thermal bridge data) a Monte Carlo simulation was performed by generating 100,000 virtual buildings and then performing the detailed calculation of the total façade thermal transmission coefficient to get a distribution of the proper thermal bridge correction factors reverse calculated from Eq. (3). The number of virtual geometries and constructional variant guarantees a sufficient coverage of possible variations. The received thermal bridge correction factor and parameter set pairs was saved for further evaluation.

In an earlier article [13] it was already shown that by varying all of the constructional (wall type, insulation type and thickness, etc.) and geometrical parameters at the same time one cannot distinguish between the influence of individual parameters and derive simplified formulas for the accurate thermal bridge correction factor. The best way to proceed is first to keep all constructional parameters constant, determine the relationship between geometry and thermal bridging for a given construction type and insulation thickness first, than the relationship between insulation thickness and thermal bridging and then the dependence on the other constructional parameters (wall type, insulation type, window type, etc.). A few examples of the calculated thermal bridge correction factors ( $X$ values) for given sets of constructional variables are plotted against the specific length of thermal bridges $(\Sigma l / A)$ in Fig. 7 Fig. 8. Each figure shows the prescribed thermal bridge correction factors of the current 
Hungarian simplified calculation method as a reference (horizontal lines), the inaccuracy of which is easy to observe.
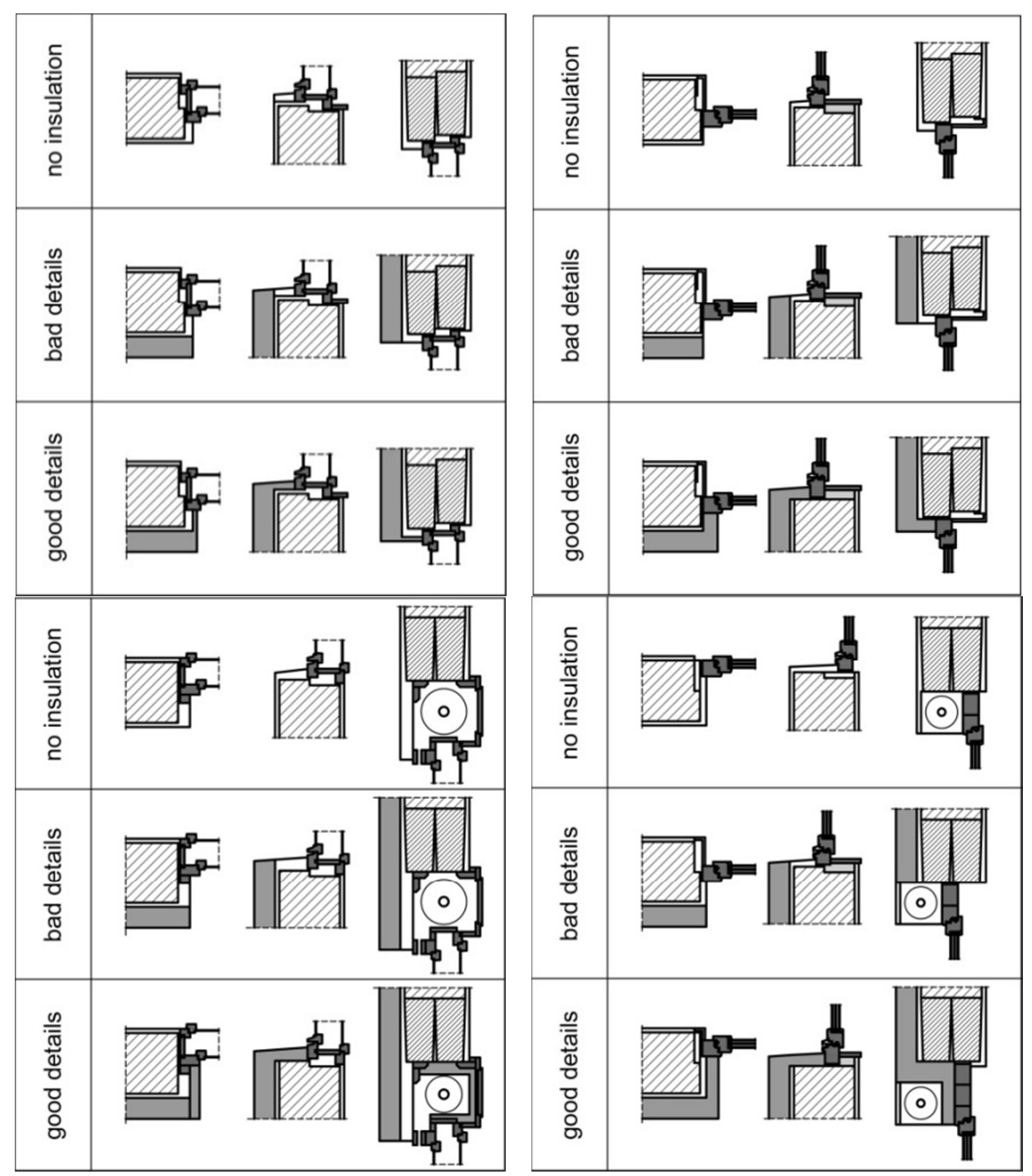

Fig. 6. 'Cube house' building type - thermal bridges of the window installation joints (window 1 (top left), window 2 (top right), window 3 (bottom left), window 4 (bottom right))

For each construction type and thermal insulation thickness (represented by individual colors and line-styles in Fig. 7-Fig. 8) there usually is a good linear correlation between $\Sigma l / A$ and $X$ (e.g. in Fig. 7 the correlation coefficient $r$ is between 0.93 and 0.94). Individual thermal bridges can have very different linear heat transfer coefficients but their relative abundance does not change much between the generated virtual facades for a given building type (for a mix of different building types or buildings that are not typical no clear correlation could be detected). It can be easy to approximate the data with a collection of fitted lines in the following form 


$$
X=a+s \frac{\sum l}{A}
$$

where $X[-]$ is the thermal bridge correction factor; $a[-]$ is the constant representing the intersection of the line with axis $y ; s[\mathrm{~m}]$ is the constant describing the slope of the line and $\Sigma l / A[1 / \mathrm{m}]$ the specific length of the thermal bridges on the façade.

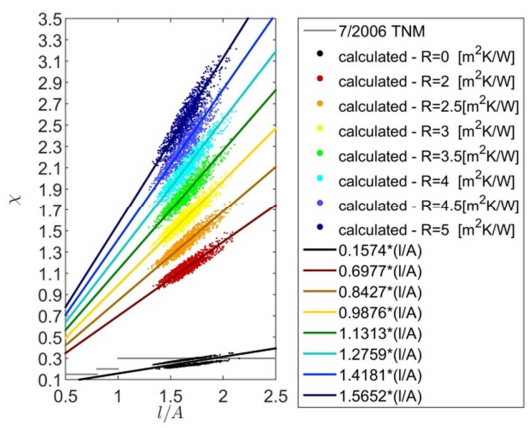

Fig. 7. Solid brick masonry, Window1, bad details, various insulation thicknesses

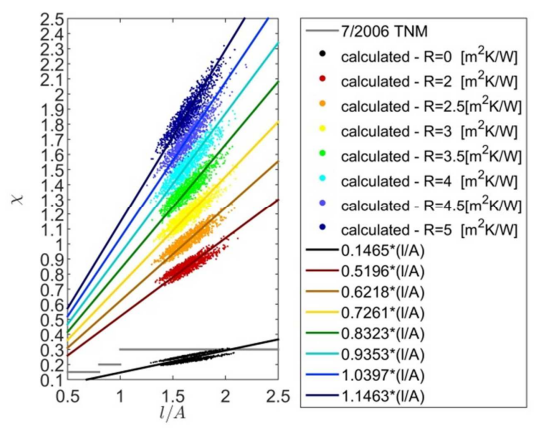

Fig. 8. Aerated clay brick mas., Window1, bad details, various insulation thicknesses

For most of cases $a$ is around zero and the lines converge in the origin of the $\Sigma l / A-$ $X$ coordinate system. This is to be expected as an imaginary façade with no thermal bridges $(l=0)$ would have no thermal bridge correction factor either. Slight deviations from this rule can exist, where the geometry and the difference in magnitude between the individual thermal bridges is more complex. The slope of the line is set by the building type and constructional variant, while the exact value along the line depends on the geometrical variation within the building type. The value of $a$ and $s$ was determined with a least squares fit for every group investigated. A derived dataset of $s$ values is summed up in Table III-Table IV for the investigated building type and constructional variants.

\section{Table III}

Summary of s values for the 'cube house' building type - Masonry: aerated clay brick

\begin{tabular}{|c|c|c|c|c|c|c|c|}
\hline \multirow{3}{*}{ detail } & & \multicolumn{7}{|c|}{$s[\mathrm{~m}]$} \\
\cline { 3 - 8 } & win. & $R_{\text {ins }}=0$ & $R_{\text {ins }}=2$ & $R_{\text {ins }}=2.5$ & $R_{\text {ins }}=3$ & $R_{\text {ins }}=4$ & $R_{\text {ins }}=5$ \\
\hline & & \multicolumn{7}{|c|}{$\left[\mathrm{m}^{2} \mathrm{~K} / \mathrm{W}\right]$} \\
\hline \multirow{5}{*}{ good } & w. 1 & 0.1463 & 0.2185 & 0.2360 & 0.2519 & 0.2863 & 0.3224 \\
& w. 2 & 0.1549 & 0.2012 & 0.2138 & 0.2264 & 0.2507 & 0.2781 \\
& w. 3 & 0.1363 & 0.2500 & 0.2769 & 0.3026 & 0.3551 & 0.4096 \\
& w. 4 & 0.1495 & 0.2313 & 0.2499 & 0.2647 & 0.2843 & 0.2821 \\
\hline \multirow{5}{*}{ bad } & w. 1 & 0.1465 & 0.5196 & 0.6218 & 0.7261 & 0.9353 & 1.1463 \\
& w. 2 & 0.1571 & 0.5611 & 0.6723 & 0.7855 & 1.0143 & 1.2415 \\
& w. 3 & 0.1543 & 0.5620 & 0.6732 & 0.7893 & 1.0182 & 1.2468 \\
& w. 4 & 0.1596 & 0.6614 & 0.7777 & 0.8866 & 1.0673 & 1.1212 \\
\hline
\end{tabular}


Table IV

Summary of s values for the 'cube house' building type - Masonry: solid brick

\begin{tabular}{|c|c|c|c|c|c|c|c|}
\hline \multirow{2}{*}{ details } & \multirow{2}{*}{ win. } & \multicolumn{7}{|c|}{$s[\mathrm{~m}]$} \\
\cline { 3 - 8 } & & $R_{\text {ins }}=0$ & $R_{\text {ins }}=2$ & $R_{\text {ins }}=2.5$ & $R_{\text {ins }}=3$ & $R_{\text {ins }}=4$ & $R_{\text {ins }}=5$ \\
\cline { 3 - 8 } & & \multicolumn{7}{|c|}{$\left[\mathrm{m}^{2} \mathrm{~K} / \mathrm{W}\right]$} \\
\hline good & w. 1 & 0.1545 & 0.2993 & 0.3302 & 0.3596 & 0.4201 & 0.4794 \\
& w. 2 & 0.1624 & 0.2670 & 0.2897 & 0.3109 & 0.3526 & 0.3945 \\
\hline bad & w. 1 & 0.1574 & 0.6977 & 0.8427 & 0.9876 & 1.2759 & 1.5652 \\
& w. 2 & 0.1641 & 0.7353 & 0.8861 & 1.0386 & 1.3395 & 1.6425 \\
\hline
\end{tabular}

The set of $s$ and $a$ values could already be useful for designers, but it contains too many data-points to be truly practical as a simplified calculation tool. An even more compact calculation method is reached by finding some relationship between the constructional parameters and the values $a$ and $s$. The form this relationship can take will wary from building type to building type depending on the number and type of the constructional parameters used to define them.

For the case of the $19^{\text {th }}$ century urban apartment buildings a relationship between the thermal resistance of the insulation, the thermal resistance of the masonry was derived (this building type has different characteristic wall thicknesses) by fitting a polynomial to the gathered data [13]. For the case of the 'cube houses' two masonry and 2-4 window types were investigated. The difference between the two wall types and between the window types would both be hard to express mathematically so it is only possible to establish a relationship between insulation thickness and $s$ value for every wall, window type and detail quality separately. A least squares fit is used with a third order polynomial of the thermal insulation's resistance:

$$
s=p_{1} R_{\text {ins }}^{3}+p_{2} R_{\text {ins }}^{2}+p_{31} R_{\text {ins }}+p_{4},
$$

where $s$ is the slope for Eq. (4) (for this building type $a=0$ ); $p_{i}$ is the polynomial coefficients (not given here) and $R_{\text {ins }}\left[\mathrm{m}^{2} \mathrm{~K} / \mathrm{W}\right]$ is the thermal resistance of the thermal insulation layer. The coefficients $p_{i}$ can be calculated once and integrated in a simple easy-to-use spreadsheet for the inexpert practitioners.

For the most cases $s$ is a near linear function of $R_{\text {ins }}$ when only the thickness of the thermal insulation is varied. For the case of window type 4 in the aerated clay brick masonry the position of the window installation in the wall was also a function of the thermal insulation thickness, which resulted in a non-linear relationship and a maximum value for $s$ around $R_{\text {ins }}=4.5\left[\mathrm{~m}^{2} \mathrm{~K} / \mathrm{W}\right]$. Among all the variants the quality of the constructional details has the largest effect on the thermal bridging. The impact of the masonry type is also significant, as it can be seen by comparing Fig 9 and Fig. 10. Even though both variants have the same overall $U$ value the thicker solid brick wall with the larger thermal conductivity causes more severe thermal bridging. The window type can cause large differences as well. The presence or absence of an inbuilt roller shutter case alone can have a comparable effect in the thermal bridging as the masonry type (see the difference between window type 1 (no shade) and type 3 (inbuilt roller shade) in Fig. 9). 


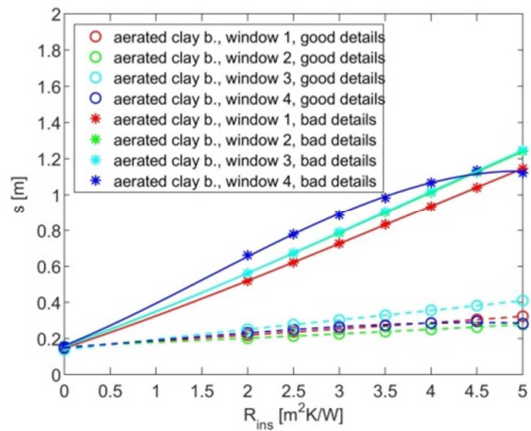

Fig. 9. 'Cube house', $25[\mathrm{~cm}]$ aerated clay brick masonry, relationship between $R_{\text {ins }}$ and $s$ and the polynomials fitted to the data

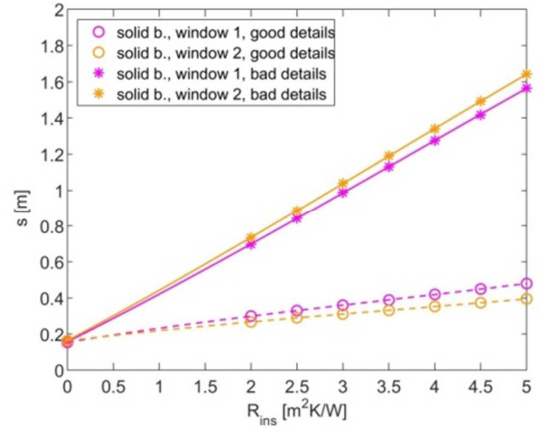

Fig. 10. 'Cube house', 38 [cm] thick solid brick masonry, relationship between $R_{\text {ins }}$ and $s$ and the polynomials fitted to the data

\section{Reducing the number of influencing parameters}

For the data presented in this study no further simplification is strictly necessary. However for the usability of the method for other variants and other building types the total number of parameters is a very important question. All investigated building types show that the value of the thermal bridge correction factor is dependent on all the parameters investigated in this study (insulation type and thickness, masonry type and thickness, detail quality, window type, etc.), it is not possible to simply eliminate any of them. The question is: which parameter can have the most number of unique values and consequently increase the total number of possible cases the most. Mathematically welldefined continuous numerical parameters, e.g. the insulation thickness can take infinitely many values (although thermal insulation is only manufactured in certain discrete thicknesses), but it is not worth to make calculations for all of them. Relationships like the one between $s, R_{\text {ins }}$ in Eq. (5) only needed a few values of $R_{\text {ins }}$ to be investigated, and once derived can provide an easy way to interpolate to new values between them.

The real difficulty with parameters is that they are mathematically not well defined and don't produce a continuous distribution of values, e.g. the window and its installation type. Any relationship for the thermal bridge correction factor is only valid for the fenestration it was derived for and no simple interpolation is possible between different variants. This is especially problematic as the window and window installation type can show the single greatest variability in buildings: window frame material, thickness, position in the masonry, shading devices, auxiliary constructions, the thermal insulation of the window reveal, etc. can all have many solutions. The 2-4 window types investigated in this study are but the tip of the iceberg.

The dependence of the correct thermal bridge correction, as demonstrated above, factor on the fenestration highlights another important point. The difference in heat losses between various window options cannot be accurately calculated by comparing only the windows' $U_{w}$ heat transfer coefficients, since the windows effect the heat flow 
in the wall around them as well. Thus a correct approach of comparing the $U$ values of windows would either have to calculate and compare the thermal bridge corrected heat transfer of the complete façade, or much more practically use the $U_{w, i n s t}$ value of the window for the comparison instead. The $U_{w, i n s t}$ value, the overall heat transfer coefficient of the window in its installed state, is often used in the design of 'passive houses' and is defined as the heat transfer coefficient that also includes the effect of the window-to-wall installation thermal bridges: $U_{w, i n s t}=\left(U_{w}{ }^{*} A_{w}+\Sigma l_{i} * \Psi_{\text {inst }, i}\right) / A_{w}$, where $U_{w}$ $\left[\mathrm{W} / \mathrm{m}^{2} \mathrm{~K}\right]$ is the heat transfer coefficient of the window on its own; $A_{w}\left[\mathrm{~m}^{2}\right]$ is the surface area of the window; $l_{i}[\mathrm{~m}]$ is the length of the window-to-wall joint $i$ and $\psi_{\text {inst }, i}[\mathrm{~W} / \mathrm{mK}]$ is the linear heat transfer coefficient of the window-to-wall joint $i$. The necessity of calculating the fenestration heat losses in this way was also demonstrated in [15]. Values of $\Psi_{\text {inst }}$ still have to be calculated with numerical simulation or taken from the literature.

As a consequence of all of this it makes sense to completely remove the window installation thermal bridges from the wall thermal bridge calculation. The simplified calculation of the external building fabric's total heat transmittance would than take the following new form (as an alternative for Eq. (1)):

$$
\dot{Q}_{\text {transm }}=\sum_{i=1}^{n} A_{i} U_{i}\left(1+\chi_{\text {new }}\left(\frac{l}{A}, \cdots\right)\right)+\sum_{k=1}^{p} A_{w, k} U_{w, \text { inst }, k}+\sum_{j=1}^{m} l_{j} \psi_{j},
$$

where $Q_{\text {transm }}[\mathrm{W} / \mathrm{K}]$ is the total heat transfer coefficient of the external thermal envelope; $A_{i}\left[\mathrm{~m}^{2}\right]$ is the internal area of the opaque surface $I ; U_{i}\left[\mathrm{~W} / \mathrm{m}^{2} \mathrm{~K}\right]$ is the thermal transmittance value of opaque surface $i$; $\chi_{\text {new }}[-]$ is the new thermal bridge correction factor (neglecting window-to-wall joints, depending on building type and constructional variant); $A_{w, k}\left[\mathrm{~m}^{2}\right]$ is the surface area of window $k ; U_{w, i n s t, k}\left[\mathrm{~W} / \mathrm{m}^{2} \mathrm{~K}\right]$ is the installed $U$ value of window $k ; l_{j}[\mathrm{~m}]$ is the length of the plinth detail $j$ (slab-on-grade perimeter) or basement wall; $\psi_{, j}[\mathrm{~W} / \mathrm{mK}]$ is the linear thermal transmittance value of the plinth or basement wall detail. This transformation has the added benefit of enabling a significant reduction in the total number of scenarios in the masonry thermal bridge correction factor's calculation. After removing the window installation thermal bridges for the investigated building type the much reduced dataset is presented in Table $V$. The greatly simple relationship is achieved by the modified thermal bridge calculation method for the investigated building types and their constructional variants (see Fig 11).

Table $V$

Summary of $s$ values for the 'cube house' building type, without the windows

\begin{tabular}{|c|c|c|c|c|c|c|c|}
\hline \multirow[b]{2}{*}{ masonry } & \multirow[b]{2}{*}{ details } & \multicolumn{6}{|c|}{$\mathrm{s}[\mathrm{m}]$} \\
\hline & & $\mathrm{R}_{\mathrm{ins}}=0$ & $\mathrm{R}_{\text {ins }}=2$ & $\mathrm{R}_{\mathrm{ins}}=2.5$ & $\mathrm{R}_{\mathrm{ins}}=3$ & $\mathrm{R}_{\mathrm{ins}}=4$ & $\mathrm{R}_{\text {ins }}=5$ \\
\hline & & \multicolumn{6}{|c|}{$\left[\mathrm{m}^{2} \mathrm{~K} / \mathrm{W}\right]$} \\
\hline \multirow[t]{2}{*}{ aer. c.b. } & good & 0.1671 & 0.2598 & 0.2729 & 0.2822 & 0.3042 & 0.3265 \\
\hline & bad & 0.1673 & 0.5569 & 0.6576 & 0.7602 & 0.9647 & 1.1710 \\
\hline \multirow[t]{2}{*}{ solid br. } & good & 0.1782 & 0.3191 & 0.3373 & 0.3524 & 0.3838 & 0.4118 \\
\hline & bad & 0.1789 & 0.6645 & 0.7897 & 0.9151 & 1.1610 & 1.4069 \\
\hline
\end{tabular}

Pollack Periodica 11, 2016, 3 


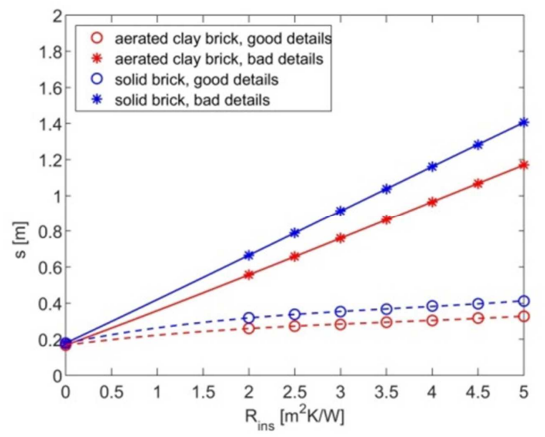

Fig. 11. 'Cube house', no windows, the calculated data points of modified method

\section{The accuracy of the proposed method}

The accuracy of the existing and the proposed new calculation method is demonstrated by analyzing the percentage error in the thermal bridge correction factors of the existing Hungarian and the proposed new simplified calculation method as:

$$
\begin{aligned}
& \% \text { Error }_{7 / 2006}=\left(\chi-\chi_{7 / 2006}\right) / \chi, \\
& \%_{\text {Error }} \text { new }=\left(\chi-\chi_{\text {new }}\right) / \chi \text {, }
\end{aligned}
$$

where \% Error $7 / 2006$ [-] and \% Error ${ }_{\text {new }}$ are the percentage errors of the exiting Hungarian simplified thermal bridge calculation method and the proposed new method respectively; $\chi[-]$ is the accurate thermal bridge correction factor; $\chi_{7 / 2006}^{[-]}$is the correction factor of the existing Hungarian and $\chi_{n e w}[-]$ is the proposed new simplified method respectively. The new method is examined both with and without the windowto-wall thermal bridges, as only the former can be directly compared to the existing Hungarian calculation method (see Fig. 12).

The existing simple calculation methods are found to be very inaccurate for all cases: it over-predicts heat losses for uninsulated buildings and significantly underpredicts after thermal insulation, depending on the detail quality and the resistance of the insulation. Both versions of the new method produce errors centered very close around 0 and with much smaller spreads. The removal of the window-to-wall thermal bridges from the proposed method may cause some errors in the case of buildings with poor thermal quality and larger variability of its façade. However the new method always produces much smaller errors than the existing calculation.

Many studies have already shown, e.g. in [16], that thermal bridges are an important factor in the quality of the external envelope, underlying the importance to calculate them accurately. This study was aimed at improving the accuracy of the thermal bridge calculation in current simplified building energy calculation methods, but contemporary trends point towards the ever grooving use of dynamic thermal simulation in building energy design, as it is demonstrated in [17] and [18]. Further work is needed to 
incorporate the devised method into dynamic building energy simulation programs. The research to find computationally affordable ways to include the dynamic behavior of multi-dimensional constructions is in its early stages, see e.g. in [19], [20] and [21], and could potentially benefit from statistical descriptions of thermal bridges.
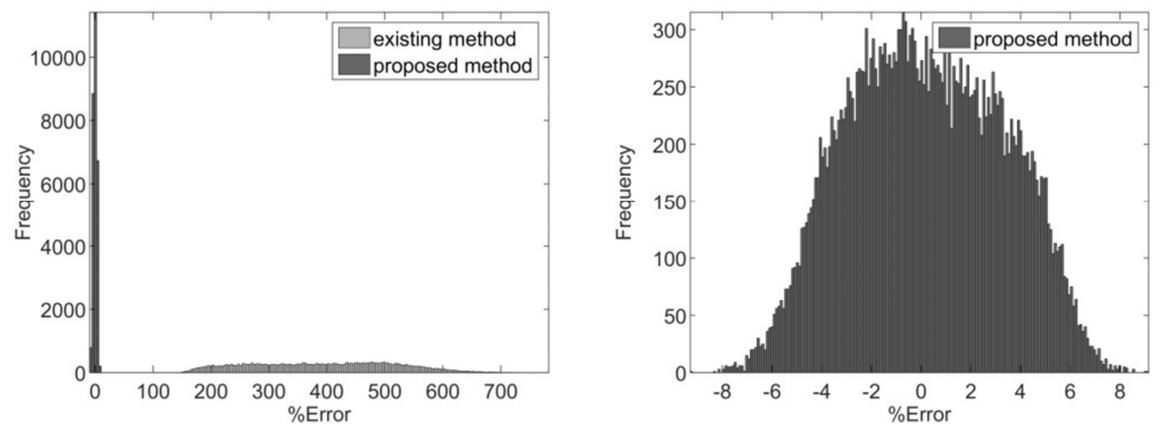

Fig. 12. 'Cube house' building type, aerated clay brick masonry, external insulation, bad details, all insulation thicknesses - histogram plot of $\%$. Error in $\chi$ for the existing and proposed methods (left) and for the proposed method without window installation thermal bridges (right)

\section{Conclusions}

The study presented in this article clearly showed that the accurate value of the thermal bridge correction factor of external walls is a function of building type, masonry type, thermal insulation position and thickness, detail quality as well as window and window installation type. Even simplified calculations of acceptable accuracy have to take all of these variables into account. The dependence of continuous variables easy to describe mathematically (e.g. insulation or masonry thickness) can be expressed with the help of simple design equations (e.g. polynomials fitted to the data).

The window and window installation type was shown to be an irreducible parameter of the thermal bridge correction. As the space of possibilities for these constructions is vast, the total number of variant to be investigated for a simplified thermal bridge calculation method is hugely increased. The proposed new equation incorporates the simplified thermal bridge calculation method and the installed or in-situ value of the fenestration $U$ value for the calculation of the thermal envelope heat transfer coefficient. By eliminating the window-to-wall connection from the list of thermal bridges that affect the corrected wall $U$ value we were are able to keep the calculation method truly simple without sacrificing accuracy.

The methodology proposed in this article should be used to develop more accurate thermal bridge correction factors for all the suitable building types and their constructional variants in Hungary to create an easy to use calculation tool for practitioners and to evaluate its effectiveness and accuracy on a wider sample. Further study is needed to quantify the effect the use of the method has on the overall accuracy of building energy calculations. 


\section{References}

[1] EN ISO 6946, Building components and building elements, Thermal resistance and thermal transmittance, Calculation method, 2007.

[2] EN-ISO-10211, Thermal bridges in building construction, Heat flows and surface temperatures, Detailed calculations, 2007.

[3] Nagy B. Comparative analysis of multi-dimensional heat flow modelling, Proc. of $2^{\text {nd }}$ Conference for PhD students in Civil Engineering, Cluj-Napoca, Romania, 2014, pp. 468-476.

[4] Vajda J., Perjési-Hámori I. Two dimensional mathematical model of heat-transmission in building structures, Pollack Periodica, Vol. 2, No. 3, 2007, pp. 25-34.

[5] Orosz M., Csanaky J. Estimating the thermal bridge at wall corners with artificial neural network, Acta Technica Jaurinensis, Vol. 8, No. 3, 2015, pp. 230-239.

[6] Citterio M., Cocco M., Erhorn-Kluttig H. Thermal bridges in the EBPD context, overview on MS approaches in regulations, Report, Assessment and Improvement of the EPBD Impact, 2008, http://www.buildup.eu/sites/default/files/P064_EN_ASIEPI_WP4_IP1_p3073.pdf, (last visited 10 February 2016).

[7] 7/2006 (V. 24.), Decree of Minister without portfolio about determination of energy efficiency of buildings, (in Hungarian) Hungarian Ministerial Decree, 2006.

[8] Nagy B. Thermal calculation of ground contact structures, Correction factors of environment- and structure-dependent effects on the heat transfer coefficient, International Journal of Computational and Experimental Science and Engineering, Vol. 1, No. 1, 2015, pp. 26-29.

[9] Bakonyi D., Dobszay G. The role of thermal bridges in the energy usage of building with valuable historical facades (in Hungarian), in Horváth, S., Pataky, R. (Eds) IV. Épületszerkezettani konferencia, Vizszigetelések, Department of Building Constructions, Budapest University of Technology and Economics, Budapest, Hungary, 19 November 2013, pp. 100-107.

[10] Csoknyai T. Monitoring of a performance oriented policy model for the retrofit of buildings built with prefabricated technology, Environmental Engineering \& Management Journal, Vol. 10, No. 9, 2011, pp. 1355-1362.

[11] Theodosius T. G., Papadopoulos A. M. The impact of thermal bridges on the energy demand of buildings with double brick wall constructions, Energy and Buildings, Vol. 40, No. 11, 2008, pp. 2083-2089.

[12] Berggren B., Wall M. Calculation of thermal bridges in (Nordic) building envelopes, Risk of performance failure due to inconsistent use of methodology, Energy and Buildings, Vol. 65, 2013, pp. 331-339.

[13] Bakonyi D., Dobszay G.: A proposed methodology for the improvement of the simplified calculation of thermal bridges for well typified facades, Periodica Polytechnica, Civil Engineering, Vol. 58, No. 4, 2014, pp. 309-318.

[14] Szalay Zs. Modelling building stock geometry for energy, emission and mass calculations, Building Research \& Information, Vol. 36, No. 6, 2008, pp. 557-567.

[15] Bakonyi D., Becker G. The heat transfer coefficient of traditional box type windows respecting the effects of the window-to-wall interface, (in Hungarian) In Horváth S., Pataky R. (Eds.) II. Épületszerkezettani konferencia: épület- és szerkezetfelújitás, Deparment of Building Constructions, Budapest University of Technology and Economics, Budapest, Hungary, 21-22 November 2011, pp. 10-18.

[16] Evola G., Margani G., Marletta L. Energy and cost evaluation of thermal bridge correction in Mediterranean climate, Energy and Buildings, Vol. 43, No. 9, 2011, pp. 2385-2393. 
[17] Baranyai B., Bachman B., Kistelegdi I. Simulation-supported design of a Hungarian national sports center, Pollack Periodica, Vol. 11, No. 1, 2016, pp. 113-127.

[18] Baranyai B., Kistelegdi I. jr. Energy management monitoring and control of public buildings, Pollack Periodica, Vol. 9, No. 2, 2014, pp. 77-88.

[19] Quinten J., Feldheim V. Dynamic modelling of multidimensional thermal bridges in building envelopes: Review of existing methods, application and new mixed method, Energy and Buildings, Vol. 110, 2016, pp 284-293.

[20] Ascione F., Bianco N., de' Rossi F., Turni G., Vanoli G. P. Different methods for the modelling of thermal bridges into energy simulation programs, Comparisons of accuracy for flat heterogeneous roofs in Italian climates, Applied Energy, Vol. 97, 2012, pp. 405-418.

[21] Brumă B., Moga L., Moga I. Aspects regarding dynamic calculation of plan building elements having thermal bridges, Energy Procedia, Vol. 85, 2016, pp 77-84. 